\title{
Self-esteem and Suicidal Risk among Subjects with Dermatological Disorders in a West African Teaching Hospital
}

\author{
O.A. Owoeye, MBChB, FMCPsych;" O.F. Aina, MBBS, FWACP;2 P.F. Omoluabi, PhD;3 \\ Y.M. Olumide, MD, FMCP, FWACP4 \\ ${ }^{1}$ Consultant Psychiatrist, Psychiatric Hospital, Yaba, Lagos \\ ${ }^{2}$ Senior Lecturer/Consultant Psychiatrist, College of Medicine, University of Lagos \\ 3 Professor of Clinical Psychology, Department of Psychology, University of Lagos \\ ${ }_{4}^{4}$ Professor/Consultant Dermatologist, College of Medicine, University of Lagos \\ Lagos, Nigeria
}

\begin{abstract}
Introduction: Skin diseases are reportedly associated with low self-esteem and can result in anxiety, depression, and suicide. The paucity of research in this important field in Nigeria necessitated this study.

Method: A prospective and cross-sectional study on attendees in the dermatology clinic of Lagos University Teaching Hospital, Lagos, Nigeria, with skin diseases $\geq 6$ months duration. An equal number of apparently healthy controls matched for age and sex also were evaluated. The subjects and controls were assessed with the sociodemographic questionnaire Index of Self-Esteem (ISE) and the subscales C, D, E, and J of the Symptom Distress Checklist-90 Revised (SCL-90-R). The data obtained was analyzed using SPSS version 10 on PC.

Results: An equal number (80) of subjects and controls, of even sex distribution with mean ages of $33 \pm 12.1$ and $34.6 \pm 7.3$ years, respectively, were studied. The common skin diseases among the subjects included acne, urticaria, vitiligo, tinea, and Hansen's disease. The mean ISE scores of the subjects and controls were $28.7 \pm 13.4$ and $21.56 \pm 10.7$, respectively, and the difference was significant with " $\mathrm{t}$ " of $3.75^{*}$. Assessment with the SCL-subscales showed the subjects' mean scores ranged from $4.7 \pm 5.4$ to $11.1 \pm 10.6$, and the controls' mean scores ranged from $2.0 \pm 3.2$ to $5.1 \pm 5.2$. The differences were significant with " $t$ " ranging from $2.75^{*}$ to $4.59 *$ (critical " $\mathrm{t}$ " $=1.66$ and $\mathrm{p} \leq 0.05$ ).

Conclusion: The subjects had statistically significant higher mean scores on assessment compared with the controls. These higher scores indicate lower selfesteem and increased risk of depression and suicide.
\end{abstract}

Key words: Self esteem, chronic skin diseases, Nigeria, suicidal risks.

O.F. Aina, MBBS, FWACP

Department of Psychiatry

College of Medicine, University of Lagos

PMB 12003

Lagos, Nigeria

e-mail:ainafran@yahoo.com
Introduction

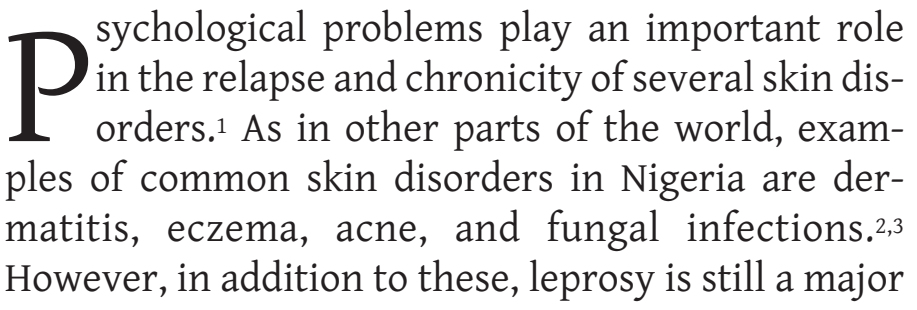


health problem in the country.4 Studies have shown that psychological factors, with or without biological factors, are sometimes responsible for causing and/or exacerbating these skin diseases. ${ }^{5}$ The effective management of at least one-third of patients attending skin clinics depends to some extent upon the recognition of associated emotional factors. ${ }^{6}$ Self-esteem is one of the most important of these emotional factors in dermatological disorders. ${ }^{7,8}$

Self-esteem has been described in various ways. Drawing together from the works of various clinicians and psychologists, self-esteem can be defined as "the sense of contentment and self acceptance that results from a person's appraisal of his own worth, significance, attractiveness, competence and ability to satisfy his aspiration." 9 Self-esteem involves both self-relevant beliefs and associated self-relevant emotions.

People with low or poor self-esteem experience negative feelings and thoughts that constantly plague them. Low self-esteem can have devastating consequences such as anxiety, stress, and increased likelihood for depression and suicide. ${ }^{10}$ Studies from Europe and the United States have shown that patients with dermatologic disorders show a high prevalence of emotional symptoms, with poor selfesteem and negative self-image being the most common.711,12 The paucity of similar work in this part of the world necessitated this study.

\section{Materials and Methods}

The study was carried out in the dermatology clinic of Lagos University Teaching Hospital (LUTH), in Lagos, Nigeria, a modern area with a local and distant client base. Study subjects were recruited from adult patients ( $\geq 21$ years) attending the clinic who had skin diseases persisting at least 6 months. Patients with comorbid chronic illnesses such as hypertension, diabetes, and hemoglobinopathy were excluded from the study. The clinic attendees were first stratified to two groups: those with their skin diseases lasting less than 6 months and those with skin diseases lasting longer than 6 months. Simple random sampling method was used to select 40 male and 40 female subjects who had skin problems lasting $\geq 6$ months. The hospital managment obtained the necessary ethical clearance. Each subject consented to be included in the study. Equal numbers of apparently healthy adults matched for age and sex among nonclinical workers at a general hospital also were recruited as controls.

An important limitation to our study was the small number of evaluated subjects. Using healthy people rather than people with nondermatological pathologies was another limitation in our study.

Appropriate sociodemographic data was obtained from each of the subjects. Furthermore, they were assessed with the Index of Self-Esteem (ISE) and the Symptom Distress Checklist-90 Revised (SCL-90-R), predominately subscales C (interpersonal sensitivity: discomfort in social situation), D (depression: loss of vital energy, interest and motivation; F (anxiety: restlessness, nervousness and tension), and J (neuroticism: poor sleep and appetite, feeling of unwellness).

The Index of Self-Esteem is a 25-item instrument developed by Hudson in 1982.13 It is designed to measure self-perceived and self-evaluative components of self-concept held by the individual. Hudson (1982) obtained an alpha coefficient of 0.93 and a two-hour test-retest coefficient of $0.92 .{ }^{13}$ Onighaiye in 1996 validated the ISE in Nigeria against the above-stated subscales of SCL-90-R. ${ }^{14}$

Derogratis et al designed SCL-90-R in 1977.15 It is a 90-item instrument with 10 subscales (A-J) to assess symptoms associated with distress among psychiatric patients, the screening of mental health complication among subjects with primary medical problems, and the experience of anguish arising from the problems of living among people in the general population. Derogatis et al obtained for the various subscales alpha coefficients ranging from 0.77 to 0.90 .15 Erinoso in 1996 validated the instrument in Nigeria. 16

Each of the subjects was assessed in the morning of their clinic days. Necessary pretest explanation and assurance of confidentiality were given. The instruments were administered to each subject so they could fill out as appropriate to their circumstance. All items in each of the instruments were cross-checked to ensure they were all answered. The same procedure was repeated for the controls. Because all the participants were literate, they required little or no assistance in the course of the data gathering.

Data analyses: Appropriate statistical analyses, such as mean scores and standard deviations, were carried out on the data obtained from the assess- 
ment with each of the instruments. Independent ttest was used to compare scores of two groups, and correlation was done to find the interrelationship among the variables. Analyses were done using SPSS version 10 on PC.

\section{Results}

Sociodemographic Findings/Dermatological Problems

Eighty subjects, equally divided between men and women with dermatological disorders, were recruited and evaluated from consecutive clinic sessions. The mean age was $33 \pm 12.1$ years. An equal number of controls matched for sex and mean age of $34.6 \pm 7.3$ years also were evaluated among the nonclinical workers of a general hospital in the neighborhood of the dermatology clinic.

Among the subjects with skin disorders, 16.3\% had acne, $13.8 \%$ had urticaria, $12.5 \%$ had vitiligo, $11.3 \%$ had tinea, and 5\% had Hansen's disease. The remaining $41.1 \%$ had other disorders such as warts, dermatitis, pruritus, and elephantiasis.

\section{Mean Scores from Assessment with ISE and SCL-90-R (subscales C, D, E, and J)}

The mean scores on ISE for male and female dermatological subjects were $28.6 \pm 13.5$ and $28.9 \pm 13.4$, respectively, with " $t$ " of 0.09 . The mean scores on ISE for male controls and female controls were $21.4 \pm 12.2$ and $21.8 \pm 9.1$, respectively, with " $t$ " of 0.18 . The mean scores for all subjects and all controls were $28.7 \pm 13.4$ and $21.6 \pm 10.7$, respectively. The difference between subjects and controls was statistically significant with " $t$ " of $3.75^{*}$ (critical " $t$ " = 1.66). Table 1 summarizes these results.

On SCL-90-R subscale C, interpersonal sensitivity, the male subjects had a mean score of $9.7 \pm 9.4$, and the male controls had a mean score of $5.1 \pm 4.7$. The female subjects had a mean score of $6.2 \pm 5.0$, and the female controls had a mean score of 5.1+5.8. The mean scores for all subjects and all controls were $7.9 \pm 7.7$ and 5.1 \pm 5.2 , respectively. The difference was statistically significant with " $t$ " of $2.75^{*}$ (critical " $t "=1.66)$.

On subscale D, depression, the mean scores for the male subjects and controls were $12.5 \pm 11.8$ and $3.8 \pm 4.2$, respectively. For the females, mean scores were $9.7 \pm 9.1$ for subjects and $5.9 \pm 7.4$ for controls. The mean scores for all subjects and all controls were $11.1 \pm 10.6$ and $4.8 \pm 6.1$, respectively, with significant "t" of $4.59^{*}$ (critical " $\mathrm{t}$ " =1.66).

On subscale E (anxiety), the male subjects and male controls had mean scores of $6.6 \pm 8.4$ and 2.3 \pm 3.9 , respectively. For females, the mean scores of the subjects and controls were $4.1 \pm 5.1$ and $2.6 \pm 5.3$, respectively. The mean scores for all subjects and all controls were $5.3 \pm 7.0$ and $2.4 \pm 4.6$ and significant " $\mathrm{t}$ " of 3.11* (critical " $t$ "=1.66).

On subscale J (neuroticism), the mean scores for the male subjects and the male controls were $5.7 \pm 6.6$ and $2.0 \pm 2.8$, respectively. The mean scores of the female subjects and the female controls were $3.7 \pm 3.7$ and $2.1 \pm 3.51$, respectively. The mean scores for all subjects and all controls were $4.7 \pm 5.4$ and $2.0 \pm 3.2$, respectively, with significant " $t$ " of $3.83^{*}$ (critical " $\mathrm{t}$ " $=1.66$ ).

Table 2 summarizes the SCL-90-R results.

\section{Discussion}

The subjects and controls were relatively young. Prevalent dermatological disorders among the subjects were common skin problems as seen in previous studies.3,12,17,18 As shown in the study, the mean scores in all the psychological measures were higher among the subjects with skin disorders than the scores among the controls. This is in line with the finding by previous authors that dermatological patients have a higher prevalence of psychological complications than the general population. ${ }^{19,20}$ The subjects with dermatological disorders had higher mean scores on ISE than the controls. This is an indication of much lower self-esteem, and this difference in the mean scores was statistically significant with " $t$ " of $3.75^{*}$ (critical " $t$ " =1.66). This finding agrees with previous studies that indicate that skin disorders such as acne and alopecia areata, which affect important body image areas cause profound lowering of confidence and self-esteem. Furthermore, the dermatological subjects had higher mean scores in the SCL-R subscales C, D, E, and J when compared to the controls. When the combined mean scores of both sexes were analyzed for the subjects and controls, the score differences were statistically significant with " $t$ " ranging from $2.75^{*}$ (subscale C) to $4.59^{*}$ (subscale D) at critical " $t$ " $=1.98$ and $p \leq 0.05$. The SCL$\mathrm{R}$ subscales used in the study measured interpersonal sensitivity (discomfort in social situations), depression (loss of vital energy, interest and motivation), anxiety (restlessness, nervousness, and ten- 
Table 1. Mean scores of subjects and controls on the Index of Self-Esteem (ISE).

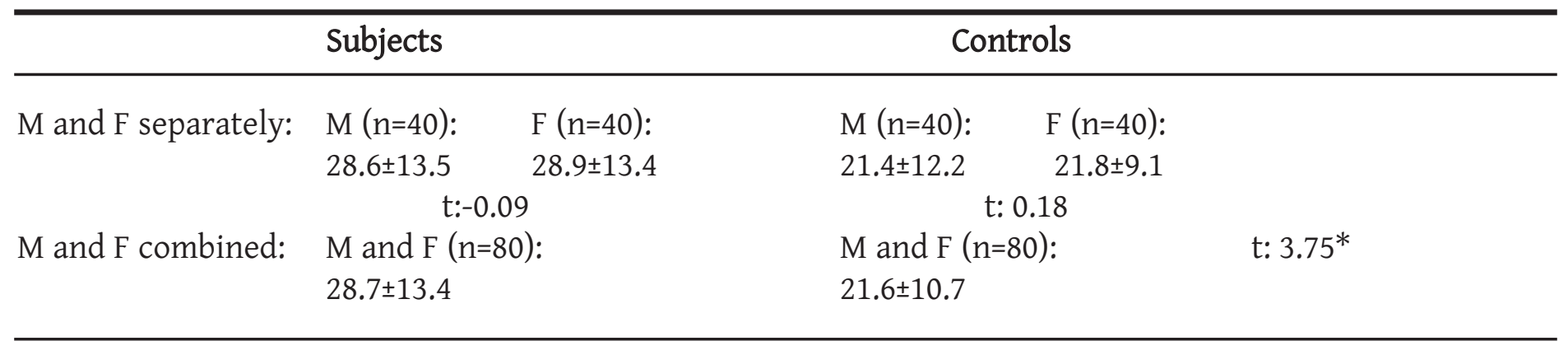

Note: *Significant critical " $\mathrm{t}$ " $=1.66, \mathrm{p} \leq 0.05$

$\mathrm{M}=$ Male, $\mathrm{F}=$ Female

Table 2. Mean scores of subjects and controls on subscales C, D, E, and J of Symptom Distress Checklist-90 Revised.

\begin{tabular}{|c|c|c|c|c|c|c|}
\hline \multicolumn{7}{|c|}{ Mean Scores of Males (M) and Females (F) separately: } \\
\hline & \multicolumn{3}{|l|}{ Subjects } & \multicolumn{3}{|l|}{ Controls } \\
\hline Subscale & $M(n=40)$ & $F(n=40)$ & "t" & $M(n=40)$ & $F(n=40)$ & "t" \\
\hline C & $9.6 \pm 9.4$ & $6.2 \pm 5.0$ & $2.06^{*}$ & $5.1 \pm 4.7$ & $5.1 \pm 5.7$ & 1.60 \\
\hline $\mathrm{D}$ & $12.5 \pm 11.8$ & $9.7 \pm 9.1$ & 1.20 & $3.8 \pm 4.2$ & $5.9 \pm 7.4$ & 0.22 \\
\hline $\mathrm{E}$ & $6.6 \pm 8.4$ & $4.1 \pm 5.1$ & 1.57 & $2.3 \pm 3.9$ & $2.6 \pm 5.3$ & 1.15 \\
\hline $\mathrm{J}$ & $5.7 \pm 6.6$ & $3.7 \pm 3.7$ & 1.66 & $2.0 \pm 2.8$ & $2.0 \pm 3.5$ & 1.33 \\
\hline \multicolumn{7}{|c|}{ Mean Scores of Males (M) and Females (F) combined: } \\
\hline Subscale & Subjects ( & & & Controls & 't" & \\
\hline C & $7.9 \pm 7.7$ & & & $5.1 \pm 5.2$ & $2.75^{*}$ & \\
\hline $\mathrm{D}$ & $11.1 \pm 10.6$ & & & $4.8 \pm 6.1$ & $4.59^{*}$ & \\
\hline E & $5.3 \pm 7.0$ & & & $2.4 \pm 4.6$ & $3.11^{*}$ & \\
\hline $\mathrm{J}$ & $4.7 \pm 5.4$ & & & $2.0 \pm 3.1$ & $3.83^{*}$ & \\
\hline
\end{tabular}

*Significant $p \leq 0.05$, critical " $\mathrm{t} "=1.98$ (2- tailed)

sion) and neuroticism (poor sleep and appetite, feeling of unwellness). These are item measures of self image, depression, and tendency to suicidality. The correlation matrix (Table 3) shows a positive correlation between the mean scores by the ISE assessment and the SCL-R subscales C,D,E, and J. The only subscale with statistically significant difference $\left(0.2^{*}\right)$ was subscale D. This finding is similar to previous ones that indicate that skin disorders that lower selfesteem could also lead to reactive depression and suicide attempts.11,21-23

The finding of poor self-esteem among our subjects is again significant as people with poor selfesteem experience negative feelings and thoughts that constantly plague them. ${ }^{24}$ Furthermore, the correlation between the mean scores on the ISE and the SCL-R subscales of C, D, E, and J in our study is in support of previous studies where low self-esteem has been found to have devastating consequences of anxiety, loneliness, and increased likelihood for depression and suicide $7,24-26$ as well as emotional pain.7,25,26 These devastating consequences are the major contents of the SCL-R subscales C, D, E, and J used in our study. Some authors have emphasized that attitude to appearance and self-report measures of the behavioral impact of skin disease, such as ISE and and the SCL-R subscales assessment used in our study, are related to psychological morbidity. ${ }^{19}$ In 
Table 3. Correlation matrix of ISE and SCL-R Subscales C, D, E, and J scores.

ISE

SCL-C 0.17

SCL-D 0.18*

SCL-E 0.14

SCL-J 0.17

${ }^{*}$ Correlation is significant at $\mathrm{p} \leq 0.05$, critical $\mathrm{r}=0.18$

our study, there is an observed gender differential among the dermatological subjects in the mean scores on both instruments. Except for the slightly lower mean score on the ISE, the male subjects had higher mean scores in other measures. However, the differences are not statistically significant, except the significant " $\mathrm{t}$ " of $2.06^{*}$ (critical " $\mathrm{t}$ " $=1.98$ ) on SCL subscale $C$ for the dermatological subjects. The greater propensity among the male dermatology patients to developing secondary mental health complications is in line with findings from previous studies.8,21,23 However, for the controls, the female subjects have slightly higher mean scores on the measurements from both instruments.

Finally, self-esteem has become an issue of importance, not only in psychiatry but in other medical fields that deal with chronic diseases with potential psychological complications and suicidality. ${ }^{27,28}$ Thus, the pursuance of self-esteem has been found to be an effective mean of reducing such possible complications and the risk of suicide. ${ }^{29}$ This is of particular importance in Nigeria, where the suicide rate has been reported to be low. However, some authors attributed this to the possibility of concealment due to legal and cultural sanctioning against suicide anddeliberate self harm. ${ }^{30,31}$ Thus, there is an urgent need to put in place consultation-liaison psychiatric services in dermatology clinics in Nigeria to minimize mental health complications among the clinic attendees.

\section{References}

1. Gupta MA, Gupta AK. Psychodermatology: an update. J Am Acad Dermatol. 1996;34;1030-46.

2. Koo JY. Psychodermatology: a practical manual for clinicians. Cur Prob Dermatol. 1995;6:204-232.

3. Alebiosu CO. Dermatology consultation in Olabisi
Onabanjo University Teaching Hospital, Sagamu. West Afr J Med. 2002;21:249.

4. Nwosu MC, Nwosu SN. Leprosy control in the post leprosaria abolition years in Nigeria: Reasons for default and irregular attendance at treatment centres. West Afr J Med. 2002;21:188-91.

5. Buljan D, Buljan M, Situm M. Psychodermatology: a brief review for clinicians. Psychiatr Danub. 2005; 17:76-83.

6. Kuruvila M, Gahalaut P, Zacharia A. A study of skin disorders in patients with primary psychiatric conditions. Indian J Dermatol Venereol Leprol. 2004;70:292-5.

7. Koblenzer CS. Stress and the skin: significance of emotional factors in dermatology. Stress Medicine. 1988;4:21-6.

8. Folks DG, Kinney FC. The role of psychological factors in dermatologic conditions. Psychosomatics. 1992;33:45-54.

9. Robson P. Development of a new self-report questionnaire to measure self esteem. Psychol Med. 1989;19:513-8.

10. McKay M, Fanning P. Self-esteem: a proven program of cognitive techniques for assessing, improving and maintaining your self-esteem. Oakland, CA: New Harbinger Publications; 2000.

11. Rubinow DR, Peck GL, Squillace KM. Reduced anxiety and depression in cystic acne patients after successful treatment with oral isotretinoin. J Am Acad Dermatol. 1987;17:25-32.

12. Gupta MA. Psychosocial aspects of common skin diseases. Can Fam Physician. 2002;4:660-2.

13. Hudson MW. Clinical measurement package: a field manual. Chicago: Dorsey Press; 1982.

14. Onighaiye MA. The impact of the length of time in the University on ego identity, self-esteem and stress manifestation in students. Unpublished B.Sc. thesis. Department of Psychology, University of Lagos, 1996.

15. Derogatis LR. SCL-90: administration, scoring and procedures manual for the r(evised) version and other instruments of the psychopathology rating scale series. Baltimore: John Hopkins University School of Medicine, Clinical Psychometrics Research Unit; 1977.

16. Erinoso OA. The sources of stress among Nigerian retirees. Unpublished BSc thesis. Department of Psychology, University of Lagos, 1996.

17. Kadri N, Moussaoui D. Dermatology and psychia- 
try. World Psychiatric Association Bulletin on Depression. 2003;7:15-20. Available from http://www.servier.com/App_Download/Neuroscie nces/WPA/WPA_26.pdf.

18. Ozumba UC, Nlemadim R. Prevalence of dermatophytosis in University of Nigeria Teaching Hospital, Enugu, Nigeria: any change in pattern? Niger J Clin Pract. 2005;8:83-5.

19. Wessely SC, Lewis GH. The classification of psychiatric morbidity in attenders at a dermatology clinic. Br J Psychiatry. 1989;155:686-91.

20. Prosperi A, Micallef J, Blin O. Utilisation de psychotropes dans la pratique dermatologique. Ann Dermatol Venereol. 2002;129:446-9.

21. Koo JY, Shellow WV, Hallman CP, et al. Alopecia areata and increased prevalence of psychiatric disorders. Int J Dermatol. 1994;33:849-50.

22. Shenefelt PD. Hypnosis in dermatology. Arch Dermatol. 2000;136:393-9.

23. Cotterill JA, Cunliffe WJ. Suicide in dermatological patients. Br J Dermatol. 1997;137:246-50.

24. Gupta MA, Gupta AK. Depression and suicidal ideation in dermatology patients with acne, alopecia areata, atopic dermatitis and psoriasis. Br J Dermatol.
1998;139:846-50.

25. Orbach I, Mikulincer M, Sirota P, et al. Mental pain: a multidimensional operationalization and definition. Suicide Life Threat Behav. 2003;33:219-30.

26. Owoeye OA, Aina OF, Omoluabi PF, et al. An assessment of emotional pain among subjects with chronic dermatological problems in Lagos, Nigeria. Int J Psychiatry Med. 2007;37:129-38.

27. Robson PJ. Self-esteem--a psychiatric view. Br J Psychiatry 1988;153:6-15.

28. Pyszczynski T, Greenberg J, Solomon S, et al. Why do people need self-esteem? A theoretical and empirical review. Psychol Bull. 2004;130:435-68.

29. Crocker J, Nuer N. Do people need self esteem? Comment on Pyszczynski et al. (2004). Psychol Bull. 2004;130:469-72.

30. Obembe A, Ilechukwu STC, Tunwashe OL, et al. Self-poisoning as seen in Lagos University Teaching Hospital: a four year review. Niger Med Pract. 1986;11:49-53.

31. Nwosu SO, Odesanmi WO. Pattern of suicides in Ile-Ife, Nigeria. West Afr J Med. 2001;20:259-62.

266). 